\title{
Two brothers with characteristic facial appearance, severe psychomotor retardation, hypospadias, contractures, and other symptoms: a new recessive syndrome?
}

\author{
G Wolff, E Zimmermann, B Zimmerhackl, C Harnasch, C Jung, E Back
}

\begin{abstract}
We report on two severely mentally retarded male children of consanguineous parents who seem to be affected by an identical syndrome. The main physical anomalies are typical facial stigmata with a broad nasal bridge, a bulbous nose, upward slanting palpebral fissures, microretrognathia, low hair line, and large ears with an incompletely developed upper helix. In addition, both brothers had hypospadias type II, limb contractures, and delayed bone age. One child had a bilateral cleft lip with cleft palate and cryptorchidism, and developed scoliosis during adolescence. The other had bilateral inguinal hernias and strabismus. Chromosome analysis showed a normal karyotype in both. The striking similarity between the brothers, the dissimilarity to other known syndromes, and the parental consanguinity argue in favour of a new, hitherto undescribed, possibly autosomal recessive syndrome.
\end{abstract}

(f Med Genet 1994;31:65-67)

Several non-chromosomal syndromes include broadening of facial midline structures like telecanthus or ocular hypertelorism together with a genital anomaly like hypo- or epispadias, the best known of which is the BBBG syndrome (MIM 145410). ${ }^{12}$ In the absence of clearly defined genetic defects, the diagnostic evaluation of a specific case depends on associated anomalies or malformations or clearly demonstrable inheritance. We report on two brothers who seem to exhibit a specific, possibly autosomal recessively inherited syndrome with midline defects and associated malformations, which is distinct from other midline defect syndromes described so far.

Case reports (table)

CASE 1 (FIGS 1A, 2A)

Case 1 was born in 1967 at term after an uneventful pregnancy and spontaneous vaginal delivery. Birth weight ( $3350 \mathrm{~g})$ and birth length $(51 \mathrm{~cm})$ were normal, but head circumference at birth is not known. Dysplastic features, recognised immediately after birth, included ocular hypertelorism, upward slanting palpebral fissures, slight creases below the eyes, a broad, bulbous nose, large ears, microretrognathia, a slight dimple in the chin, broad thumbs, hyperconvex nails, and clinodactyly V. He had a bilateral cleft lip and palate that had to be repeatedly operated on, as well as hypospadias and bilateral inguinal testes. His further development was characterised by severe motor and mental retardation. He was able to sit only at the age of 2 years and to walk after his fifth year. There was no speech development. At the age of 19, height $(157 \mathrm{~cm})$, weight $(41 \mathrm{~kg})$, and head circumference $(53 \mathrm{~cm})$ were within normal limits (both parents smaller than $160 \mathrm{~cm}$ ), but he had developed scoliosis and peripheral contractures especially of the interphalangeal joints II and IV and of the feet (supination position). At the age of 22 , he was incontinent, unable to speak, and did not establish social contact.

Routine laboratory findings were within normal limits and ultrasound of the kidneys

The main features of the syndrome in the brothers described here

\begin{tabular}{lll}
\hline & Case 1 & Case 2 \\
\hline Severe mental retardation & + & + \\
Epilepsy & - & + \\
Ocular hypertelorism & + & + \\
Bulbous nose & + & + \\
Upward slanting palpebral fissures & + & + \\
Micro/retrognathia & + & + \\
Low hair line & + & + \\
Large ears & + & + \\
Cleft lip and palate & + & - \\
Convergent strabismus & - & + \\
Abnormal nasal septum & - & + \\
Thick lips & + & + \\
Genitalia & & \\
$\quad$ Hypospadias & + & + \\
$\quad$ Inguinal hernias & - & + \\
Delayed skeletal maturation & + & - \\
Scoliosis & + & + \\
Limb contractures, postnatal, & + & - \\
$\quad$ progressive & + & + \\
Terminal hypoplasia of fingers & + & + \\
Talipes & + & + \\
Contractures of large joints & - & + \\
Camptodactyly & + & + \\
Clinodactyly & + & - \\
Rough skin & + & + \\
\hline
\end{tabular}




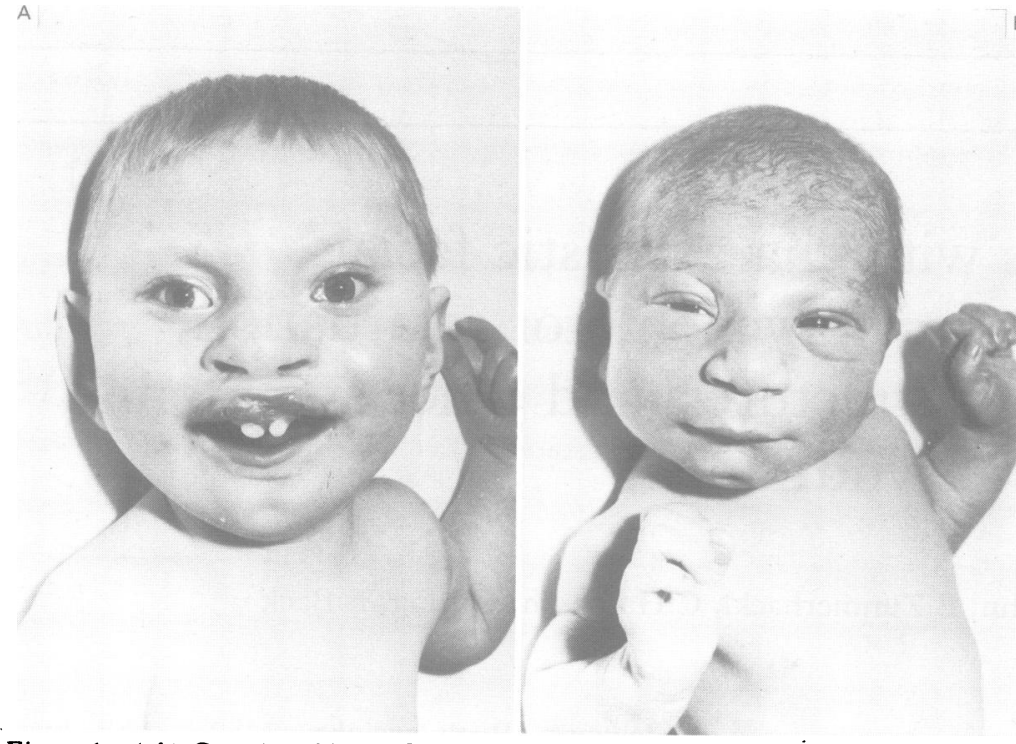

Figure 1 (A) Case 1 at 20 months. (B) Case 2 at birth. Note the upward slanting palpebral fissures, telecanthus, broad nose, and microretrognathia.

and ECG showed no abnormalities. $X$ rays showed a delayed bone age. Radiological findings in the thorax were normal, but showed a subphrenic displacement of the colon (Chilaiditi syndrome). EEG was non-specifically altered, but he did not have any epileptic seizures. His chromosomes were normal (46,XY, 550 bands/haplotype). Unfortunately, testing for the fragile site at Xq27 was not performed, and the parents refused another blood sampling for this investigation or for molecular analysis.

CASE 2 (FIGS 1B, 2B)

Case 2 was born in 1971 at term without complications, but Apgar scores indicated a short period of respiratory distress (Apgar scores $5 / 7 / 10)$. Birth weight $(3520 \mathrm{~g}$ ), length $(50 \mathrm{~cm})$, and head circumference $(33 \mathrm{~cm})$ were

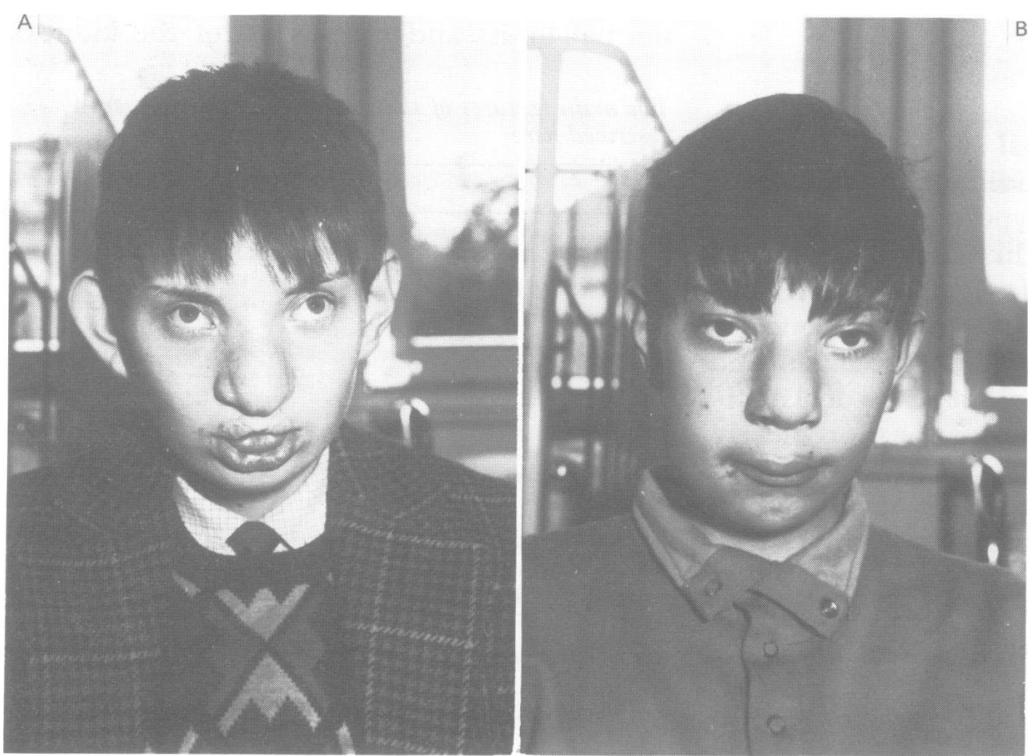

Figure 2 ( $A$ ) Case 1 at 22 years. (B) Case 2 at 18 years. Both have a low frontal hair line, large ears, telecanthus, and upward slanting palpebral fissures, a broad bulbous nose, and microretrognathia. Case 1 shows scars after operations for bilateral facial clefting. normal. The dysmorphic features observed postnatally were more pronounced than in his brother with a sloping forehead, broad nose, telecanthus, deep creases below the eyes, marked microretrognathia, and a deep dimple in the chin. The hands seemed broad and plump and the skin felt rough. External malformations included hypospadias and bilateral inguinal hernias. He developed strabismus at the age of 1 year. His psychomotor development was severely retarded, although not as marked as that of his older brother. He learned to walk at the age of about 3 years. At the age of 12 he could speak only a few words and his speech was very indistinct. He was incontinent and unable to cooperate during clinical examination. Up to this age, he had had one epileptic seizure, but the EEG was only nonspecifically altered. At 18 years, height $(156 \mathrm{~cm})$, weight $(45 \mathrm{~kg})$, and head circumference $(51 \mathrm{~cm})$ were within normal limits. The facial dysplastic symptoms were strikingly similar to his brother's. In addition to the peripheral joint contractures found in his brother, he had developed proximal (hip, knees) contractures. He was operated on for nasal septum deviation. Routine laboratory findings in the blood were within normal limits and the pyelogram and ECG were also normal. $X$ rays showed a delayed bone age like in his brother.

\section{FAMILY HISTORY}

These brothers are the only children of a healthy couple from Italy. At delivery of the boys, the maternal age was 21 and 25 years, and the paternal age 23 and 27 years respectively. A third pregnancy ended in an early spontaneous abortion. The mother's relatives were healthy, except for one cousin who was said to be blind and to have died at the age of 2 years of unknown causes. A nephew of the father died shortly after birth because of spina bifida, and one of his uncles was said to be mildly mentally retarded. The parents are third cousins once removed. There was no relative known to them with identical or similar features to those observed in their sons.

\section{Discussion}

Both sons of this consanguineous couple apparently suffer from an identical MCA/MR syndrome. A computer assisted syndrome search (POSSUM) based on the main features of these patients did not show any other identical case published up to now. Six syndromes exhibit four of the five major symptoms: hypertelorism, broad or bulbous nasal tip, hypospadias, camptodactyly, and mental retardation, but five of them can safely be excluded on the grounds of other obligatory symptoms. In the branchioskeletogenital syndrome, ${ }^{3}$ fused cervical vertebral spiny processes and mandibular cysts are observed. The Cohen-Lockwood-Wyborney syndrome (POSSUM No 3966) is accompanied by blepharophimosis, ptosis, and syndactyly. The 
main features of the MCA Braegger-Bottani type $^{4}$ are polydactyly, conductive deafness, and renal malformations. Children with Marden-Walker syndrome ${ }^{5}$ exhibit blepharophimosis and myopathy, and usually die in the first months of life. The Weaver-Williams syndrome $^{6}$ is characterised by a small face and thin body.

The sixth syndrome found, acrofrontofacionasal dysostosis, has to be taken into consideration. The facial appearance of our two boys shows striking features in common with the brother and sister described by RichieriCosta et al. ${ }^{7}$ As "marked anomalies of foot structures" we found talipes in both boys, and as hand anomalies camptodactyly and terminal hypoplasia of the fingers, but there is no brachypolysyndactyly or fibular hypoplasia. The boys' short stature seems to be related to the short stature of both parents. Both brothers are mentally retarded like the sibs reported by Richieri-Costa et al. ${ }^{7}$ However, further symptoms like upward slanting palpebral fissures, a broad but not notched nasal tip, marked retrognathia, hypospadias, progressive limb contractures, and large hands are evidence in favour of a distinct syndrome.

In the broader differential diagnosis three syndromes have to be taken into consideration. The BBBG (Opitz) syndrome (MIM 145410) ${ }^{12}$ is characterised by malformations of the midline structures with telecanthus, broad nasal root, functional defect or optional clefting of the larynx or the oesophagus or both that may lead to repeated aspiration, hypospadias and other genital malformations, and also malformations of the heart, the urogenital tract, anal stenosis or imperforate anus, and facial clefting. Mental retardation is only found in half of the cases and therefore is not an obligatory finding. Because of proven father-son inheritance, ${ }^{8}$ it has been assumed that the BBBG syndrome is an autosomal dominant disorder that is mainly diagnosed in males because of the hypospadias as a major symptom.

The patients described here exhibit ocular hypertelorism and hypospadias as symptoms of a midline defect but none of the other symptoms typical of the BBBG syndrome. The shape of the nose in both boys is strikingly different from that in the BBBG syndrome which is characterised by anteverted nostrils. Moreover, neither of the affected brothers suffers from respiratory distress, and progressive joint contractures are not considered to be features of the BBBG syndrome. The family history is also not in favour of this diagnosis with none of the parents or relatives showing any of the features of the BBBG syndrome.

Malpuech et al ${ }^{9}$ reported on four children of a consanguineous couple who had mental and pre- and postnatal growth retardation, hypertelorism, facial clefting, urogenital malformations, and normal chromosomes. However, the facies of these four children is quite different from that in the two brothers reported here with their characteristic broad nose, sloping forehead, and microretrognathia. Moreover, considering their parents' stature, the height of the two brothers has to be regarded as normal.

Lindstrom $^{10}$ described sibs of unrelated parents who had growth retardation (adult height of the male $140 \mathrm{~cm}$ and of the female $120 \mathrm{~cm}$ ), severe mental retardation, camptoand clinodactyly, and facial stigmata (large, broad nose, thick lips with lateral clefting, broad nose, large dysplastic ears) which show some similarity to those in the brothers. However, microcephaly, dwarfism, and no hypospadias clearly distinguish Lindstrom's patients from ours.

Therefore we assume that the two brothers described here probably suffer from a hitherto undescribed genetic syndrome. The findings of unaffected parents and relatives together with consanguinity of the parents are in favour of autosomal recessive inheritance, but $\mathrm{X}$ linkage cannot be totally excluded.

1 Opitz JM. Editorial comment. G syndrome (hypertelorism with esophageal abnormality and hypospadias, or hypospadias-dysphagia, or 'Opitz-Frias' or 'Opitz-G' syndrome): perspective in 1987 and bibliography. $A m$ synGenet 1987;28:275-85.

2 Cappa M, Borelli P, Marini R, Neri G. The Opitz syndrome: a new designation for the clinically indistinguishable $\mathrm{BBB}$ and $\mathrm{G}$ syndromes. Am $\mathrm{f}$ Med Genet 1987;28:303-9.

3 Elsahy NI, Witkop CJ Jr. Branchio-skeleto-genital syndrome. In: Buyse ML, ed. Birth defects compendium. Oxford: Blackwell Scientific Publications, 1990:245-6.

4 Braegger C, Bottani A, Giedion A, et al. Unknown syndrome: ischiadic hypoplasia, renal dysfunction, immunodrome: ischiadic hypoplasia, renal dysfunction, immunoMed Genet 1991;28:56-9.

5 Jaatoul NY, Haddad NE, Khouri LA, et al. The MardenWalker syndrome. Am $\mathcal{F}$ Med Genet 1982;11:259-71.

6 Weaver DD, Williams CPS. A syndrome of microcephaly mental retardation, unusual facies, cleft palate, and weight deficiency. Birth Defects 1977;XIII(3b):69-84.

7 Richieri-Costa A, Colletto GMDD, Gollop TR, Masiero D. A previously undescribed autosomal recessive multiple congenital anomalies/mental retardation (MCA MR) syndrome with fronto-nasal dysostosis, cleft lip/ palate, limb hypoplasia, and postaxial poly-syndactyly: acro-fronto-facio-nasal dysostosis syndrome. $\mathrm{Am} \mathcal{J} \mathrm{Med}$ Genet 1985;20:631-8.

8 Stoll C, Geraudel A, Berland H, Roth MP, Dott B. Maleto-male transmission of the hypertelorism-hypospadias (BBB) syndrome. Am $\mathcal{F}$ Med Genet 1985;20:221-5.

9 Malpuech G, Demeocq F, Palcoux JB, Vanlieferinghen P. A previously undescribed autosomal recessive multiple congenital anomalies/mental retardation (MCA/MR) syndrome with growth failure lip/palate cleft(s) urogenital anomalies. Am f Med Genet 1983;16:475-80.

10 Lindstrom JA. GG-oligophrenic, low birthweight dwarfism in sibs. Birth Defects 1975;11(2):443-9. 